\title{
Transforming growth factor- $\beta 1$ enhances the invasiveness of breast cancer cells by inducing a Smad2-dependent epithelial-to-mesenchymal transition
}

\author{
ZHI-DONG LV ${ }^{1}$, BIN KONG ${ }^{1}$, JIAN-GUO LI ${ }^{1}$, HUI-LI QU ${ }^{1}$, XIN-GANG WANG ${ }^{1}$, WEI-HONG CAO ${ }^{1}$, \\ XIAO-YI LIU ${ }^{1}$, YU WANG ${ }^{1}$, ZHAO-CHUAN YANG ${ }^{2}$, HUI-MIAN XU ${ }^{3}$ and HAI-BO WANG ${ }^{1}$ \\ Departments of ${ }^{1}$ Breast Surgery and ${ }^{2}$ Child Health Care, The Affiliated Hospital of Qingdao \\ University Medical College, Qingdao 266003; ${ }^{3}$ Department of Surgical Oncology, \\ The First Hospital of China Medical University, Shenyang 110001, P.R. China
}

Received July 1, 2012; Accepted August 28, 2012

DOI: $10.3892 /$ or.2012.2111

\begin{abstract}
Metastasis is unequivocally the most lethal aspect of breast cancer and the most prominent feature associated with disease recurrence, the molecular mechanisms whereby epithelial-to-mesenchymal transition (EMT) mediates the initiation and resolution of breast cancer metastasis remains poorly understood. Transforming growth factor- $\beta 1$ (TGF$\beta 1)$ is a multifunctional cytokine that is intimately involved in regulating numerous physiological processes, including cellular differentiation, homeostasis and EMT. Recent findings have implicated high levels of TGF- $\beta 1$ were associated with poor outcome, whereas inhibition of TGF- $\beta$ signaling reduces metastasis in breast cancer, suggesting that the chemotherapeutic targeting of TGF- $\beta 1$ or TGF- $\beta$ signaling may offer new inroads in ameliorating metastatic disease in breast cancer patients. In this study, we showed immunohistochemical evidence for EMT, which is associated with TGF- $\beta 1$ expression, at the invasion front of breast cancer in vivo. The data also indicated that human breast cancer cell lines, MCF-7 and MDA-MB-435S, of epithelial cell characteristics were induced to undergo EMT by TGF- $\beta 1$ and dependent on the Smad2 signaling pathway. Following TGF- $\beta 1$ treatment, cells showed dramatic morphological changes assessed by phase contrast microscopy, accompanied by decreased epithelial marker and increased mesenchymal markers. Importantly, cell invasion was
\end{abstract}

Correspondence to: Dr Hai-Bo Wang, Department of Breast Surgery, The Affiliated Hospital of Qingdao University Medical College, Shandong, Qingdao 266003, P.R. China

E-mail: qingyiwhb@126.com

Dr Hui-Mian Xu, Department of Surgical Oncology, The First Hospital of China Medical University, Liaoning, Shenyang 110001, P.R. China

E-mail: xuhuimianpf@163.com

Key words: breast cancer, epithelial-to-mesenchymal transition, transforming growth factor- $\beta 1, \operatorname{Smad} 2$, invasion also enhanced in the EMT process, while knockdown of the Smad2 gene by silencing siRNA partially inhibited these effects in MDA-MB435S $(\mathrm{P}<0.05)$. These data suggested that EMT of breast cancer induced by TGF- $\beta 1$ is dependent on Smad2 signaling and promotes breast cancer cell metastasis.

\section{Introduction}

Breast cancer is one of the major causes of death in women, $\sim 350,000$ women die from breast cancer each year (1). However, most mortality and morbidity does not arise from the primary tumor, but from distant metastasis (2). In order to metastasize a cancercell must shed many of its epithelial characteristics, invade the surrounding tissue to enter the circulation, subsequently survive in the circulation, extravasate and proliferate in the metastatic niche (3). Invasion is therefore a key step in the metastatic cascade. Targeted therapy for metastatic disease is clinically unavailable because the molecular mechanism underlying metastasis remains unclear (4). Thus, identifying functional metastasis genes and their molecular mechanisms underlying the metastatic process remains a top priority in the cancer research field.

Recent research has demonstrated that epithelial-to-mesenchymal transition (EMT) plays a key role in the early process of metastasis of cancer cells (5). Greenburg and Hay (6) first described that epithelial cells cultured in vitro might acquire mesenchymal features, providing the proof of principle for the process of EMT. The transition of epithelial cells into mesenchymal cells, known as EMT, is a process during which cells undergo a morphological switch from the epithelial polarized phenotype to a highly motile fibroblastic or mesenchymal phenotype (7). In the EMT process, epithelial cells lose their features, gain mesenchymal properties, and become motile and invasive. The feature of EMT is the reduction of cell-cell adhesion, especially the reduction of E-cadherin which is critical to maintain the epithelial structure. It has been reported that the loss of E-cadherin expression is correlated with tumor invasion and metastasis (8). With the loss of E-cadherin expression, the expression of mesenchymal markers, vimentin and fibronectin, can be upregulated when EMT occurs $(7,9)$. 
Transforming growth factor- $\beta 1$ (TGF- $\beta 1$ ) signals have an important role in the metastatic spread of cancer cells, such as migration, invasion, and EMT $(7,10,11)$. Overexpression of TGF- $\beta 1$ is reported to be correlated with poor prognosis of breast tumours, especially basal-like and luminal type of cancers, suggesting that TGF- $\beta$ signaling might have an important role in the progression of breast cancer cells $(12,13)$. Therefore, inhibition of TGF- $\beta$ signaling in breast carcinoma may yield beneficial effects through inhibition of invasion and metastasis of cancer. TGF- $\beta 1$ mediates EMT by inducing Smad signaling $(7,14,15)$. Smads are a group of intracellular proteins that are critical for transmitting the TGF- $\beta 1$ signals from the cell surface to the nucleus in order to promote transcription of target genes (16). The role of Smad3 in the development of EMT has been reported $(17,18)$. However, the potential role of Smad2 in the development of EMT is unclear.

To understand the role of EMT in breast cancer metastasis and its mechanism, we demonstrated in this study that TGF- $\beta 1$ induced a series of EMT-associated changes in breast cancer is dependent on the Smad2 signaling and promoted tumor progression and metastasis by means of EMT.

\section{Materials and methods}

Reagents. Total Smad2, phosphorylated Smad2, $\alpha$-SMA, vimentin, cytokeratin, TGF- $\beta 1$ and E-cadherin antibodies, as well as secondary antibodies were purchased from Santa Cruz Biotechnology, Inc. (Santa Cruz, CA, USA). The transwell chamber was obtained from Corning Life Sciences (NY, USA). DMEM and fetal calf serum were purchased from Gibco-BRL (Carlsbad, CA, USA). Human TGF- $\beta 1$ was obtained from Sigma (St. Louis, MO, USA). Other laboratory reagents were obtained from Sigma.

Cell line and culture. Two human breast cancer cell lines, MCF-7 and MDA-MB-435S, were obtained from the Cancer Research Institute of Beijing, China. These cells were cultivated in T75 tissue culture flasks in DMEM supplemented with $10 \%$ fetal calf serum, $100 \mathrm{IU} / \mathrm{ml}$ penicillin, $100 \mu \mathrm{g} / \mathrm{ml}$ streptomycin, $2 \mathrm{mM}$ L-glutamine, and $20 \mathrm{mM}$ hydroxyethyl piperazine ethanesulfonic acid, and incubated in a humidified incubator containing $5 \% \mathrm{CO}_{2}$ at $37^{\circ} \mathrm{C}$.

Tissue immunohistochemistry and scoring. Breast tumor samples from 128 patients who underwent surgery in the Affiliated Hospital of Qingdao University Medical College between March 2011 and October 2011, were studied. The local institutional review board approved our protocol for use of patient samples; all patients provided written informed consent prior to participation in the study. Three $5-\mu \mathrm{m}$ frozen sections were taken from these specimens and stained with hematoxylin and eosin (H\&E). The original histologic diagnosis used for clinical management was confirmed by three independent, expert histopathologists. Cases were selected based on a confirmed diagnosis of breast cancer and the presence of both an invasive margin and a central tumor area on the same section. Several criteria to verify the presence of an invasion front were assessed. H\&E was used to identify single cells, which appeared to be at the tumor edge. Samples with invasion fronts identified on $\mathrm{H} \& \mathrm{E}$ criteria were then subjected to immunohistochemistry using i) MNF116, a pan cytokeratin marker (1:50) to identify epithelial cells, and ii) CD45, a hematopoietic cell marker (1:100) to confirm that cells identified as possibly invasive were not in fact inflammatory.

Eighteen carcinoma samples from patients that fulfilled these stringent criteria were selected, and a further thirty $5-\mu \mathrm{m}$ sections of these samples were then cut. An additional H\&E section was stained, and the remaining sections were used for immunohistochemistry. Tissue was fixed with acetone for $10 \mathrm{~min}$ and rehydrated with ethanol. Slides were blocked with $10 \%$ horse serum for $1 \mathrm{~h}$ at room temperature and incubated with cytokeratin (1:50), E-cadherin (1:100), vimentin (1:200), and TGF- $\beta 1$ (1:50) antibodies overnight at $4^{\circ} \mathrm{C}$. Slides were incubated with anti-mouse biotinylated secondary antibody (1:200). Finally, detection was carried out with the DAB kit according to the manufacturer's instructions. Each slide had at least three replicate sections for each antibody. Quantitative analysis of cytokeratin and vimentin staining in the central tumor area compared with the invasive margin was done by two independent observers. The invasive front was identified and the area of central tumor most distant from this invasive front was then selected, and three independent fields were scored for staining intensity and for cellular localization of cytokeratin staining. The intensity of staining was scored as 0 (none), 1 (weak), 2 (mild), 3 (moderate), and 4 (strong) compared with a negative (no primary antibody) and positive control. The cellular localization of cytokeratin was classified as membranous, cytoplasmic or mixed.

Phase contrast microscopy. The phenotypic changes of breast cancer cells were determined by phase contrast microscopy. The cancer cells in cultures treated with recombinant TGF- $\beta 1$ and left untreated (control) for $72 \mathrm{~h}$ and morphological changes were visualized by phase contrast microscopy. The images were collected using Nikon inverted microscope.

Western blot analysis. Breast cancer cells were cultured on a 6 -well tissue culture plate to confluence. The cell were treated with recombinant human TGF- $\beta 1$ at the time of switching to serum-free medium, at a final concentration of $5 \mathrm{ng} / \mathrm{ml}$. The cancer cells cultured without TGF- $\beta 1$ were considered as control. The cells were harvested at $72 \mathrm{~h}$. Total cellular protein was extracted using a lysis buffer and quantified using protein quantification reagents from Bio-Rad. Next, $60 \mu \mathrm{g}$ of the protein was suspended in $5 \mathrm{X}$ reducing sample buffer, boiled for $5 \mathrm{~min}$, electrophoresed on $10 \%$ SDS-PAGE gels, and then transferred to polyvinylidene difluoride membrane by electroblotting. The membrane was blocked in $1 \% \mathrm{BSA} / 0.05 \%$ Tween/PBS solution overnight at $4{ }^{\circ} \mathrm{C}$, followed by incubation with the primary antibody (mouse monoclonal antibodies to either human $\alpha$-SMA, vimentin, cytokeratin, E-cadherin, phosphorylated-Smad2, or Smad2) for $24 \mathrm{~h}$. A horseradish peroxidase-labelled goat antimouse IgG was used as the secondary antibody. The blots were then developed by incubation in a chemiluminescence substrate and exposed to X-ray film.

Small interfering-RNA (siRNA) treatment. The breast cancer cells were grown to a $70 \%$ confluence on culture dishes and the transient transfection was performed with specific stealth small interference RNA against Smad2, or control siRNA over- 

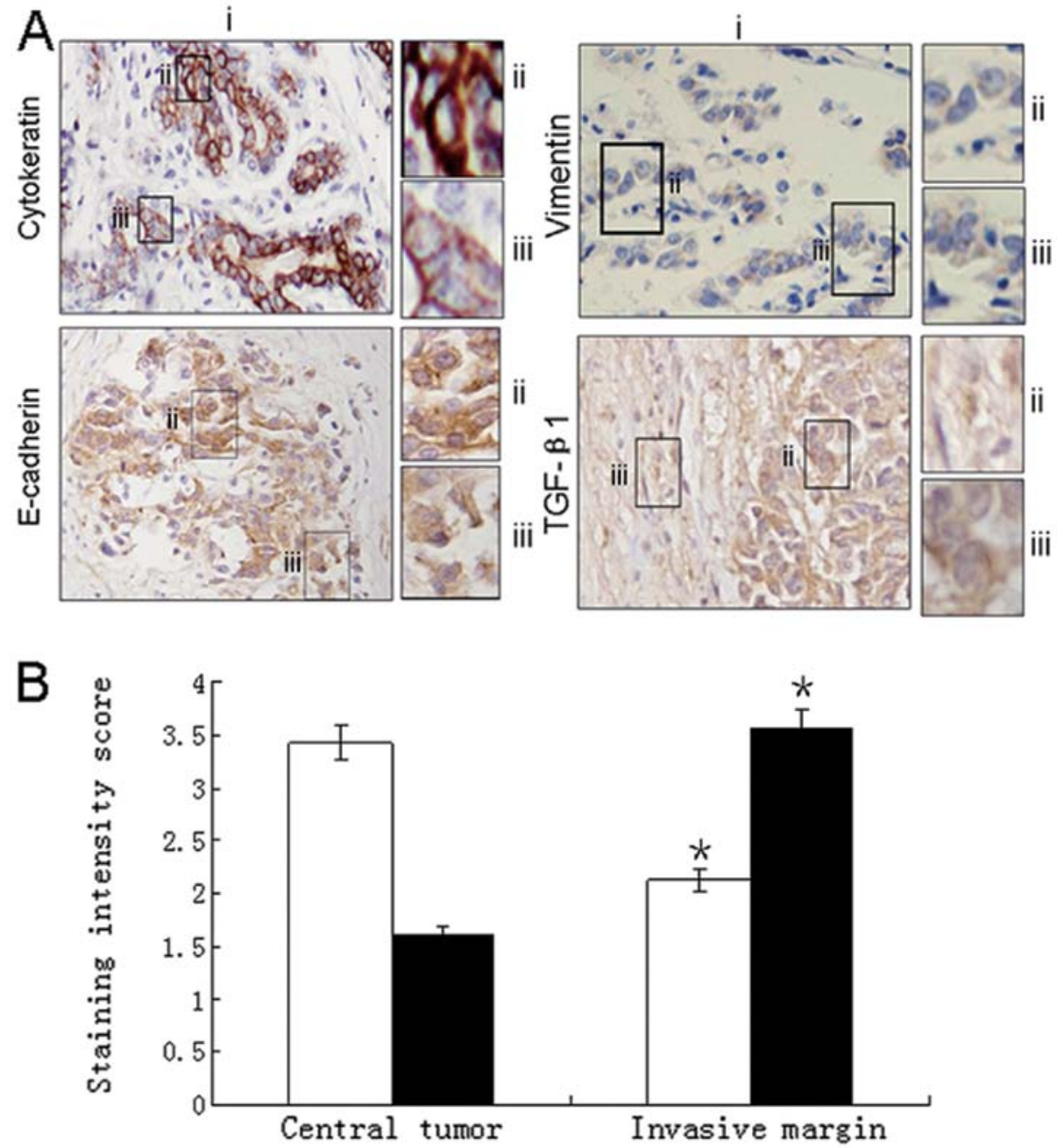

Figure 1. Cytokeratin, E-cadherin, vimentin and TGF- $\beta 1$ expression at the the central tumor area and invasive margin. (A) Representative immunohistochemical staining for cytokeratin, E-cadherin, vimentin and TGF- $\beta 1$. i) Tumor containing the invasive margin at low-power image (magnification, $\mathrm{x} 100)$ with representative high-power images (magnification, x100). Black frames, areas selected from the low-power field show ii) the central tumor area and iii) invasive margin. (B) Quantitative assessment of immunohistochemistry for intensity of cytokeratin (white columns) and vimentin (black columns) staining of the central tumor compared with the invasive margin. ${ }^{*} \mathrm{P}<0.05$ as compared the central tumor with the invasive margin for the same marker.

night using Lipfectamine-2000, according the manufacturer's instructions. The total of two siRNA sequences for Smad2 and control-siRNA were designed and synthesized from Invitrogen using RNAi designer software program. The concentration of $300 \mathrm{nM}$ was determined to be the most effective siRNA concentration for Smad2 silencing. The transfection medium was changed with culture medium containing 5\% FBS for $24 \mathrm{~h}$. TGF- $\beta 1$ at final concentration of $5 \mathrm{ng} / \mathrm{ml}$ was added to the cell cultures in serum-free medium or without TGF- $\beta 1$ (control). The cells were harvested at 4,24 and $72 \mathrm{~h}$ for further experiments.

Invasion assay. In vitro invasiveness was measured by the method described in the study by Albini et al (19), with some modifications. We used chemotaxis chambers with a $8 \mu \mathrm{m}$-pore membrane filter coated with $50 \mathrm{mg}$ of matrigel in a 24-well culture plate. MDA-MB-435S cells were pretreated with TGF- $\beta 1$ or Smad2-siRNA, and plated at a concentration of $3 \times 10^{5} / \mathrm{ml}$ per upper well in $200 \mu \mathrm{l}$ of serum-free medium. As a chemoattractant, $10 \%$ fetal calf serum medium was used in the lower chamber. After being recultured with $5 \% \mathrm{CO}_{2}$ at $37^{\circ} \mathrm{C}$ for $24 \mathrm{~h}$, the filters were removed, fixed in $95 \%$ alcohol, and stained with trypan blue. The cells remaining on the top surface of the membrane were completely removed with a cotton swab, and the membrane was removed from the chamber and mounted on a glass slide. The number of infiltrating cancer cells were counted in five regions selected at random, and the extent of invading cancer cells was determined by the mean count.

Statistical analysis. All values in the text and figures are presented as mean \pm SD. In univariate analysis, 2-tailed $\chi^{2}$ tests for categorical variables and 2-tailed t-test for continuous variables were used for statistical comparisons. Values of $\mathrm{P}<0.05$ were taken to show a significant difference between means.

\section{Results}

Increased expression of mesenchymal markers at invasion front. Immunohistochemical analysis of the invasive component of carcinoma specimens was compared with the central area of the tumor. There was downregulation of the intensity of the epithelial staining with E-cadherin and cytokeratin at the 

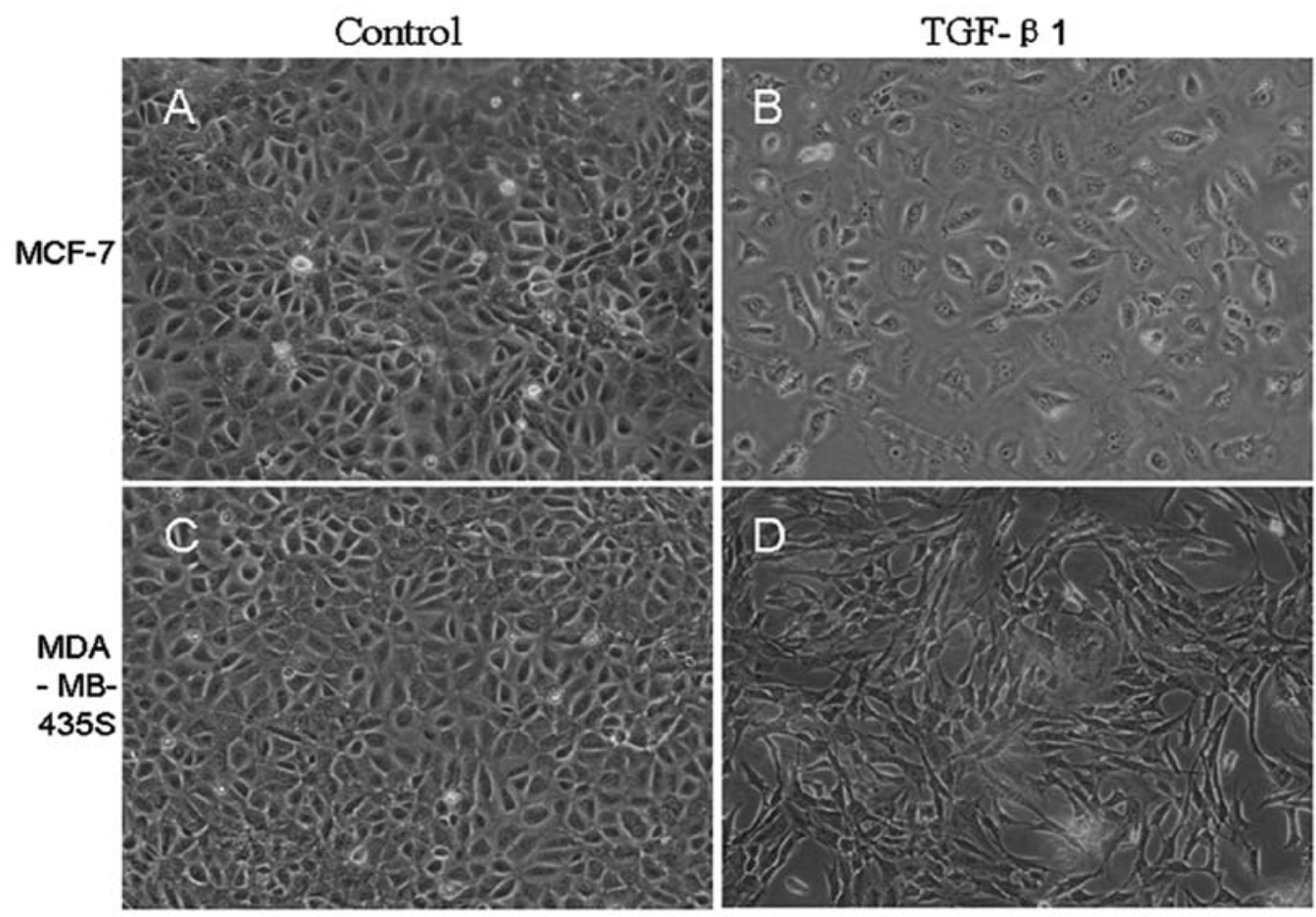

Figure 2. Phase-contrast microscopy observed the morphological changes of breast cancer cells. (A and C) The breast cancer cells, MCF-7 and MDA-MB$435 \mathrm{~S}$, without the treatment of TGF- $\beta 1$ as control. (B and D) The breast cancer cells, MCF-7 and MDA-MB-435S, treated by TGF- $\beta 1$ ( $5 \mathrm{ng} / \mathrm{ml})$ for $72 \mathrm{~h}$. All images were obtained at a magnification of $\mathrm{x} 100$.

A

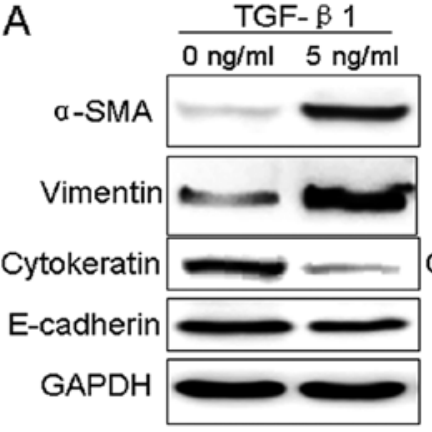

B

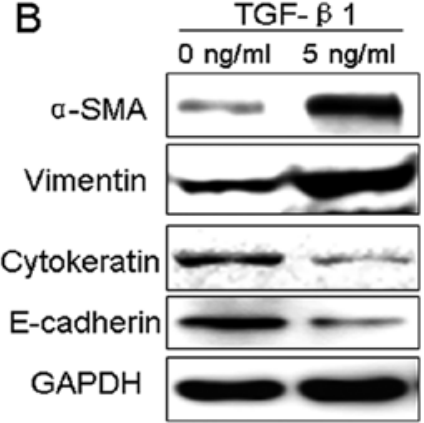

Figure 3. Effects of TGF- $\beta 1$ on the expression of $\alpha$-SMA, vimentin, E-cadherin, and cytokeratin in cancer cells. The cancer cells were treated with TGF- $\beta 1(5 \mathrm{ng} / \mathrm{ml})$ for $72 \mathrm{~h}$, and the expression of $\alpha$-SMA, vimentin, cytokeratin, and E-cadherin were evaluated by western blotting in MCF-7 (A) and MDA-MB-435S (B). The blot was re-probed for GAPDH to ensure equal loading of protein in each lane.

invasive tumor margin. Furthermore, there was a redistribution of E-cadherin staining from a predominantly membranous pattern in the central area to a predominantly cytoplasmic pattern at the margin. In contrast, a low intensity of vimentin staining was observed in the center of the tumor compared with increased intensity of expression at the invasive margin. Quantification of cytokeratin and vimentin staining intensity showed downregulation of cytokeratin at the invasive margin $(\mathrm{P}<0.005)$ and a contrasting upregulation of vimentin staining $(\mathrm{P}<0.05)$. Staining for $\mathrm{TGF}-\beta 1$ showed a predominantly stromal expression pattern in both the central and invasive tumor components with foci of increased uptake in the invasive front (Fig. 1).
Morphological changes of breast cancer cells. In the absence of TGF- $\beta 1$, small portions of cell morphology were somewhat mesenchymal, but most breast cancer cells showed pebble-like shape and tight cell-cell adhesion. However, after TGF- $\beta 1$ treatment for $72 \mathrm{~h}, \mathrm{MCF}-7$ and MDA-MB-435S cells showed morphological changes assessed by phase contrast microscopy. Many cells assumed more elongated shape and lost contact with their neighbor, displaying fibroblast-like appearance compared to the untreated cells (Fig. 2).

TGF- $\beta 1$ induces EMT marker changes in breast cancer cells. To better confirm morphological changes in breast cancer cells, MCF-7 and MDA-MB-435S cells, represent EMT, western blotting was used to examine the changes of EMT-related protein markers. The results indicated that the expression of cytokeratin and E-cadherin, the epithelial phenotype marker, was significantly decreased in MDA-MB-435S cells, while TGF- $\beta 1$ did not affect the E-cadherin expression levels in MCF-7. Those of mesenchymal phenotype markers, $\alpha-S M A$ and vimentin, were greatly increased in MCF-7 and MDA-MB435S cells (Fig. 3).

Effects of TGF- $\beta 1$ or siRNAi-Smad2 on Smad2 phosphorylation of breast cancer cells. Here we showed that Smad2 phosphorylation was increased by TGF- $\beta 1$ in MCF-7 and MDA-MB- 435S, while TGF- $\beta 1$ did not affect the total Smad2 expression levels. In order to confirm whether $\operatorname{Smad} 2$ is involved in TGF- $\beta 1$ mediated EMT of breast cancer, siRNAs were used to knockdown the Smad2 gene in MDA-MB-435S. As shown in Fig. 4B, siRNAi-Smad2\#1 highly significant knockdown for Smad 2 and phosphorylated $\mathrm{Smad} 2$ when compared to the other siRNAs or the control. 
A
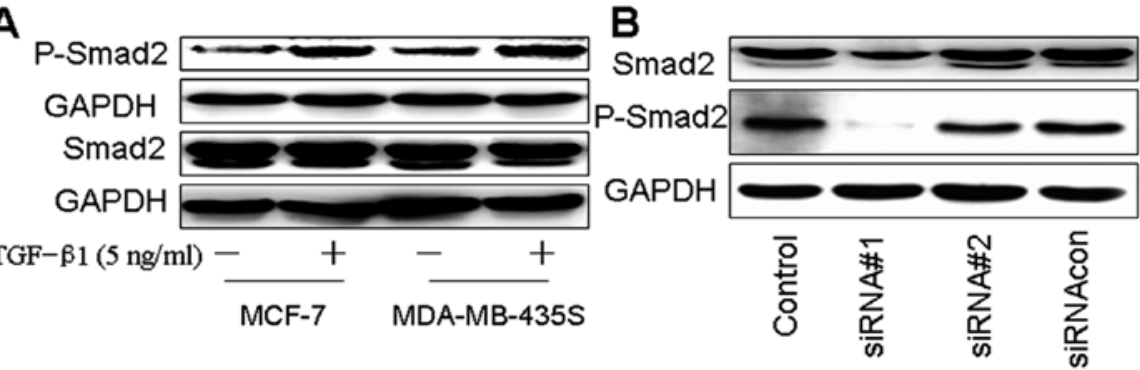

Figure 4. Smad 2 siRNA suppresses the expression of Smad 2 in TGF- $\beta 1$ activated breast cancer cells. (A) The cancer cells were treated with TGF- $\beta 1$ ( 5 ng/ml) for $72 \mathrm{~h}$, and the expression of phosphorylated forms of Smad2 and Smad2 were evaluated by western blotting in MCF-7 and MDA-MB-435S. (B) The cancer cells was transfected with siRNA Smad 2 and activated with TGF- $\beta 1$ for $4 \mathrm{~h}$, the expression of phosphorylated forms of Smad 2 and Smad 2 were evaluated in MDA-MB-435S. GAPDH was used as a loading control to demonstrate equal protein loading.

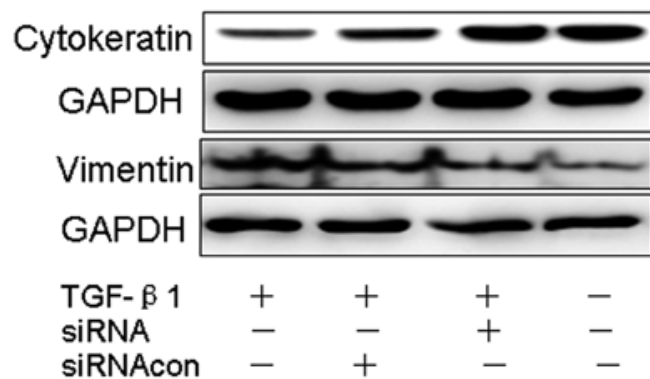

Figure 5. Vimentin and cytokeratin expression in MDA-MB-435S. Serumstarved cancer cells were transfected with siRNA-Smad2 or control siRNA and treated with TGF- $\beta 1(5 \mathrm{ng} / \mathrm{ml})$ for $72 \mathrm{~h}$, vimentin and cytokeratin expression in MDA-MB-435S were measured by western blotting. GAPDH was used as a loading control to demonstrate equal protein loading.

Silencing Smad 2 signaling blocks TGF- $\beta 1$-induced mesenchymal transformation in MDA-MB-435S. After silencing Smad 2 by using siRNA-Smad2 or control-siRNA in cancer cells treated with TGF- $\beta 1$, we noted a remarkably reduced expression of vimentin, and most importantly a significant restoration of the junctional protein cytokeratin suggesting a role for Smad2 signaling in EMT of cancer cells (Fig. 5).

Promotion of cell invasion induced by TGF- $\beta 1$. We analyzed the invasion capability of the highly metastatic MDA-MB-435S cells using the methods described above. The results showed that TGF- $\beta 1$ significantly promoted the invasiveness of cells when compared to control $(\mathrm{P}<0.05)$, While Smad2-siRNA significant decreased the number of invasive cells under TGF- $\beta 1$ stimulation $(\mathrm{P}<0.05)$. These results suggested EMT of breast cancer induced by TGF- $\beta 1$ promote cancer cells metastasis, but knockdown of the Smad2 gene, by silencing siRNA reduced the invasion of gastric cancer cells can partially inhibit these effects (Fig. 6).

\section{Discussion}

In this study, we showed immunohistochemical evidence for EMT, which is associated with TGF- $\beta 1$ expression at the invasion front of breast cancer in vivo. A TGF- $\beta 1$-induced in vitro model of EMT showed morphologic, molecular, and functional evidence for this process that was reversible by Smad2 RNAi.
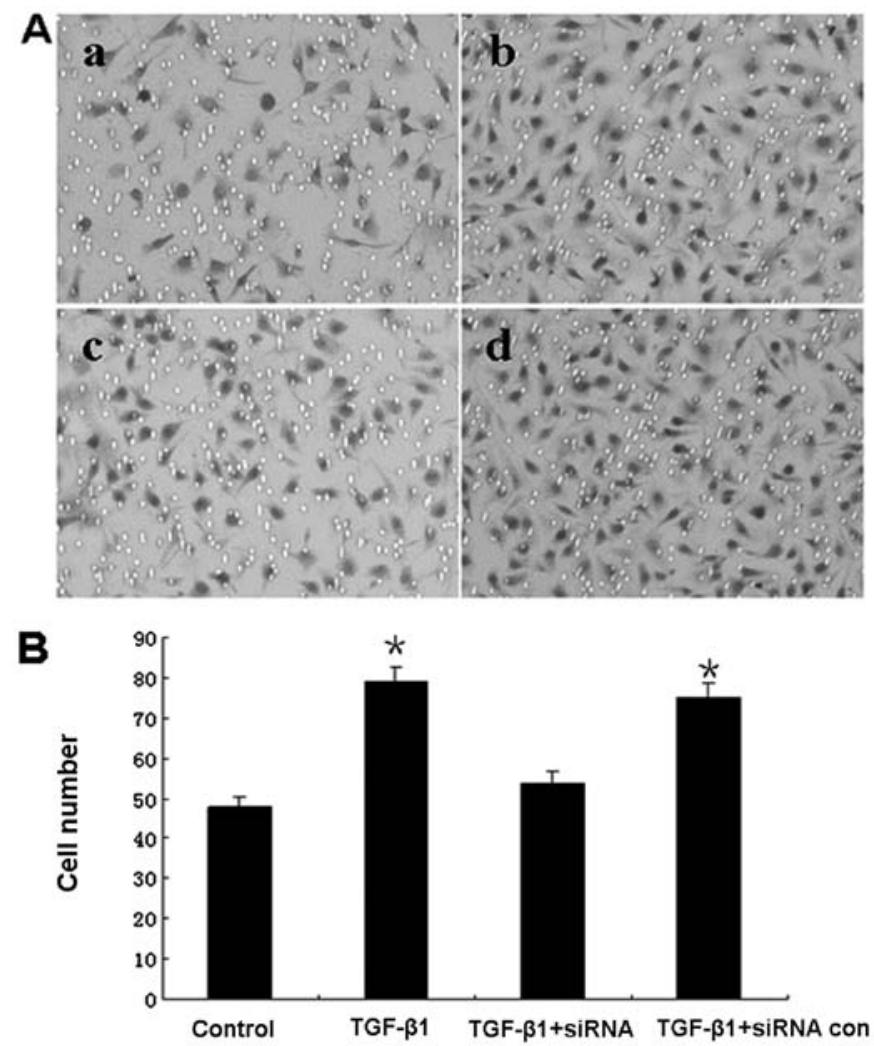

Figure 6. Effect of TGF- $\beta 1$ on MDA-MB-435S cell invasion. (A) Breast carcinoma cells were plated in the upper chamber of transwells and incubated for $24 \mathrm{~h}$. For the inhibition experiment, the cancer cells were (a) untreated as a control; (b) treated with TGF- $\beta 1(5 \mathrm{ng} / \mathrm{ml})$ for $72 \mathrm{~h}$; (c) transfected with siRNA-Smad 2 and treated with TGF- $\beta 1$ for $72 \mathrm{~h}$; (d) transfected with control siRNA and treated with TGF- $\beta 1$ for $72 \mathrm{~h}$. (B) The columns indicate the number of cells invaded at the 24-h time point. The assays were carried out in triplicate. ${ }^{*} \mathrm{P}<0.05$ as compared with control (magnification, $\mathrm{x} 40$ )

The differential expression of epithelial and mesenchymal markers has been recognized in several rare tumors of mixed phenotype $(20,21)$. More recently, this differential expression of epithelial and mesenchymal markers at the invasive margin has been described in colorectal and hepatocellular tumors $(22,23)$, suggesting that EMT might be a feature of the invasive characteristics of epithelial tumors. In addition, changes suggestive of EMT have been described in cell lines, such as nonmalignant Madin-Darby canine kidney cells, and cell lines derived from the pancreas cancers (24). 
The molecular and phenotypic changes from an epithelial to a mesenchymal cell type seem to be functionally relevant because several studies have shown that EMT is important in cancer progression $(25,26)$. During EMT, epithelial cell-cell contact is decreased by the downregulation of cytoskeletal components and the cell morphology becomes more fibroblastlike with upregulation of mesenchymal markers, including $\alpha$-SMA and vmentin $(27,28)$. Loss of the classic epithelial marker E-cadherin is associated with poor outcome in several tumor sites, including invasive ductal breast carcinoma (29), and gastric adenocarcinoma (30). A reduction in E-cadherin level is considered as a hallmark of EMT. E-cadherin plays a key role in maintaining the epithelial structural integrity and polarization, loss of which consequently destabilizes the structural integrity of epithelium and makes cells dissociate from their neighbors (31). Our data demonstrated that breast cancer cells undergo transition from the epithelial to the mesenchymal phenotype upon activation with TGF- $\beta 1$, with the induction of the transcription factor Smad2 and the expression changes of EMT-related proteins occurred in MDA-MB-435S. However, the E-cadherin expression did not change in MCF-7. We concluded that MDA-MB-435S, but not MCF-7, was prone to undergo a complete EMT. EMT may contribute to greater motility and higher invasiveness of tumor cells.

Smads are a group of intracellular proteins that are critical for transmitting the TGF- $\beta 1$ signals from the cell surface to the nucleus to promote transcription of target genes $(14,16)$. Accumulating evidence indicates that TGF- $\beta$ stimulates cancer cell EMT and metastasis through a combination of Smad2/3dependent and -independent signaling systems. Engineering metastatic human MCF10ACA1a breast cancer cells to express a dominant-negative Smad3, or a T $\beta$ R-I mutant incapable of activating Smad2/3, significantly reduced the ability of MCF10ACA1a cells to colonize the lung (32). In the present study, we demonstrated the role of Smad 2 in TGF- $\beta 1$ mediated EMT in MDA-MB-435S. The significance of the present study is that breast cancer cells undergo the process of EMT via expression of the mesenchymal markers vimentin and $\alpha$-SMA, and siRNA-Smad2 significantly blocked the expression of vimentin in cancer cells activated with TGF- $\beta 1$ and prevented EMT.

In the context of epithelial cancer, EMT provides a mechanism for tumor cells to leave the primary tumor and invade into the local tissue and blood vessels, setting the stage for metastatic spread (33). Therefore, EMT is hypothesized to contribute to tumor progression, and indeed clinical evidence suggests that regulators of EMT, such as TGF- $\beta 1$, in cancer cells correlate with poor patient outcomes and tumor aggressiveness $(13,34)$. To evaluate these biological functions of the cells undergoing EMT and if Smad2 siRNA could reduce this abilty of invasion, we used invasion assays in our study. Our results showing cells undergoing EMT by the stimulation with TGF- $\beta 1$ were more invasive. Consistently, the inhibition of TGF/Smad2 pathway by siRNA led to a signifcant decrease the abilty of invasion.

In summary, we showed immunohistochemical evidence for EMT, which is associated with TGF- $\beta 1$ expression at the invasion front of breast cancer in vivo. Furthermore, the exposure of breast cancer cell lines to TGF- $\beta 1$ results in EMT, marked by changes in cell morphology, cell behavior, and expression of EMT-related protein markers, whereas knockdown of the
Smad2 gene by silencing siRNA partially inhibited these effects. Collectively, our current data demonstrated that EMT of breast cancer induced by TGF- $\beta 1$ is dependent on Smad2 signaling and promotes breast cancer cell metastasis.

\section{References}

1. Porter PL: Global trends in breast cancer incidence and mortality. Salud Publica Mex 51: 141-146, 2009.

2. Naber HP, Wiercinska E, Pardali E, van Laar T, Nirmala E, Sundqvist A, van Dam H, van der Horst G, van der Pluijm G, Heckmann B, Danen EH and Ten Dijke P: BMP-7 inhibits TGF- $\beta$ induced invasion of breast cancer cells through inhibition of integrin $\beta(3)$ expression. Cell Oncol 35: 19-28, 2012.

3. Ding Z, Wu CJ, Chu GC, Xiao Y, Ho D, Zhang J, Perry SR, Labrot ES, Wu X, Lis R, Hoshida Y, Hiller D, Hu B, Jiang S, Zheng H, Stegh AH, Scott KL, Signoretti S, Bardeesy N, Wang YA, Hill DE, Golub TR, Stampfer MJ, Wong WH, Loda M, Mucci L, Chin L and DePinho RA: SMAD4-dependent barrier constrains prostate cancer growth and metastatic progression. Nature 470: 269-273, 2011.

4. Gu Y, Mi W, Ge Y, Liu H, Fan Q, Han C, Yang J, Han F, Lu X and $\mathrm{Yu}$ W: GlcNAcylation plays an essential role in breast cancer metastasis. Cancer Res 70: 6344-6351, 2010.

5. Polyak K and Weinberg RA: Transitions between epithelial and mesenchymal states: malignant and stem celltraits. Nat Rev Cancer 9: 265-273, 2009.

6. Greenburg G and Hay ED: Epithelia suspended in collagen gels can lose polarity and express characteristics of migrating mesenchymal cells. J Cell Biol 95: 333-339, 1982.

7. Lv ZD, Na D, Ma XY, Zhao C, Zhao WJ and Xu HM: Human peritoneal mesothelial cell transformation into myofbroblasts in response to TGF- $\beta 1$ in vitro. Int J Mol Med 27: 187-193, 2011.

8. Uchikado Y, Okumura H, Ishigami S, Setoyama T, Matsumoto M, Owaki T, Kita Y and Natsugoe S: Increased Slug and decreased E-cadherin expression is related to poor prognosis in patients with gastric cancer. Gastric Cancer 14: 41-49, 2011.

9. Yanez-Mo M, Lara-Pezzi E, Selgas R, Ramirez-Huesca M, Dominguez-Jimenez C, Jimenez Heffernan JA, Aguilera A, Sanchez-Tomero JA, Bajo MA, Alvarez V, Castro MA, del Peso G, Cirujeda A, Gamallo C, Sanchez-Madrid F and Lopez-Cabrera M: Peritoneal dialysis and epithelial-to-mesenchymal transition of mesothelial cells. N Engl J Med 348: 403-413, 2003.

10. Kang Y, Siegel PM, Shu W, Drobnjak M, Kakonen SM, CordónCardo C, Guise TA and Massagué J: A multigenic program mediating breast cancer etastasis to bone. Cancer Cell 3: 537-549, 2003.

11. Katsuno Y, Hanyu A, Kanda H, Ishikawa Y, Akiyama F, Iwase T, Ogata E, Ehata S, Miyazono K and Imamura T: Bone morphogenetic protein signaling enhances invasion and bone metastasis of breast cancer cells through Smad pathway. Oncogene 7: 6322-6333, 2008.

12. Padua D, Zhang XH, Wang Q, Nadal C, Gerald WL, Gomis RR and Massagué J: TGFbeta primes breast tumors for lung metastasis seeding through angiopoietin-like 4. Cell 133: 66-77, 2008.

13. Benson JR: Role of transforming growth factor beta in breast carcinogenesis. Lancet Oncol 5: 229-239, 2004.

14. Xu J, Lamouille S and Derynck R: TGF-beta-induced epithelial to mesenchymal transition. Cell Res 19: 156-172, 2009.

15. Shibata S, Marushima H, Asakura T, Matsuura T, Eda H, Aoki K, Matsudaira H, Ueda $\mathrm{K}$ and Ohkawa K: Three-dimensional culture using a radial flow bioreactor induces matrix metalloprotease 7-mediated EMT-like process in tumor cells via TGF $\beta 1 /$ mad pathway. Int J Oncol 34: 1433-1448, 2009.

16. Heldin CH, Miyazono K and ten Dijke P: TGF- $\beta$ signalling from cell membrane to nucleus through SMAD proteins. Nature 390: 465-471, 1997.

17. Liu Q, Mao H, Nie J, Chen W, Yang Q, Dong X and Yu X: Transforming growth factor beta1 induces epithelial-mesenchymal transition by activating the JNK-Smad3 pathway in rat peritoneal mesothelial cells. Perit Dial Int 3: 88-95, 2008.

18. Yoo YA, Kang MH, Kim BS, Kim JS and Seo JH: Sustained co-cultivation with human placenta-derived MSCs enhances ALK5/Smad3 signaling in human breast epithelial cells, leading to EMT and differentiation. Differentiation 77: 450-461, 2009.

19. Albini A and Benelli R: The chemoinvasion assay: a method to assess tumor and endothelial cell invasion and its modulation. Nat Protoc 2: 504-511, 2007. 
20. Wick MR and Swanson PE: Carcinosarcomas: current perspectives and an historical review of nosological concepts. Semin Diagn Pathol 10: 118-127, 1993.

21. Thompson L, Chang B and Barsky SH: Monoclonal origins of malignant mixed tumors (carcinosarcomas). Evidence for a divergent histogenesis. Am J Surg Pathol 20: 277-285. 1996.

22. Brabletz T, Herrmann K, Jung A, Faller G and Kirchner T: Expression of nuclear h-catenin and c-myc is correlated with tumor size but not with proliferative activity of colorectal adenomas. Am J Pathol 156: 865-870, 2000.

23. Giannelli G, Bergamini C, Fransvea E, Sgarra C and Antonaci S: Laminin- 5 with transforming growth factor- $\beta 1$ induces epithelial to mesenchymal transition in hepatocellular carcinoma. Gastroenterology 129: 1375-1383, 2005.

24. Tojo M, Hamashima Y, Hanyu A, Kajimoto T, Saitoh M, Miyazono K, Node M and Imamura T: The ALK-5 inhibitor A-83-01 inhibits Smad signaling and epithelial-to-mesenchymal transition by transforming growth factor-beta. Cancer Sci 96 : 791-800. 2005

25. Scheel C and Weinberg RA: Phenotypic plasticity and epithelialmesenchymal transitions in cancer and normal stem cells? Int J Cancer 129: 2310-2314, 2011.

26. Jiang J, Tang YL and Liang XH: EMT: a new vision of hypoxia promoting cancer progression. Cancer Biol Ther 11: 714-723, 2011.

27. Vered M, Dayan D, Yahalom R, Dobriyan A, Barshack I, Bello IO, Kantola S and Salo T: Cancer-associated fibroblasts and epithelial-mesenchymal transition in metastatic oral tongue squamous cell carcinoma. Int J Cancer 127: 1356-1362, 2010.
28. Jin H, Morohashi S, Sato F, Kudo Y, Akasaka H, Tsutsumi S, Ogasawara H, Miyamoto K, Wajima N, Kawasaki H, Hakamada K and Kijima H: Vimentin expression of esophageal squamous cell carcinoma and its aggressive potential for lymph node metastasis. Biomed Res 31: 105-112, 2010

29. ElMoneim HM and Zaghloul NM: Expression of E-cadherin, $\mathrm{N}$-cadherin and snail and their correlation with clinicopathological variants: an immunohistochemical study of 132 invasive ductal breast carcinomas in Egypt. Clinics 66: 1765-1771, 2011.

30. Mimata A, Fukamachi H,Eishi Y and Yuasa Y: Loss of E-cadherin in mouse gastric epithelial cells induces signet ring-like cells, a possible precursor lesion of diffuse gastriccancer. Cancer Sci 102: 942-950, 2011.

31. Gavert N and Ben-Ze'ev A: Epithelial-mesenchymal transition and the invasive potential of tumors. Trends Mol Med 14 199-209, 2008

32. Ge R, Rajeev V, Ray P, Lattime E, Rittling S, Medicherla S, Protter A, Murphy A, Chakravarty J, Dugar S, Schreiner G, Barnard $\mathrm{N}$ and Reiss $\mathrm{M}$ : Inhibition of growth and metastasis of mouse mammary carcinoma by selective inhibitor of transforming growth factor-beta type I receptor kinase in vivo. Clin Cancer Res 12: 4315-4330, 2006.

33. Ansieau S, Caron de Fromentel C, Bastid J, Morel AP and Puisieux A: Role of the epithelial-mesenchymal transition during tumor progression. Bull Cancer 97: 7-15, 2010 (In French).

34. Buck MB, Fritz P, Dippon J,Zugmaier G and Knabbe C: Prognostic significance of transforming growth factor beta receptor II in estrogen receptor-negative breast cancer patients. Clin Cancer Res 10: 491-498, 2004. 